\title{
Expression of Collagen Types I, II and III in Juvenile Angiofibromas
}

\author{
M. Gramann ${ }^{a} \quad$ O. Wendler ${ }^{a} \quad$ L. Haeberle ${ }^{b} \quad$ B. Schick ${ }^{a}$ \\ ${ }^{a}$ Department of Otolaryngology, Head and Neck Surgery and ${ }^{b}$ Institute of Medical Informatics, Biometry and \\ Epidemiology, University Erlangen-Nuremberg, Erlangen, Germany
}

\section{Key Words}

Juvenile angiofibroma $\cdot$ Extracellular matrix $\cdot$ Collagens findings confirming that collagen type Il expression is practically absent in JAs refutes the theory that JAs originate in cartilage tissue.

Copyright $\odot 2008$ S. Karger AG, Base

\begin{abstract}
Extracellular matrix components have rarely been the focus of interest in juvenile angiofibroma (JA) studies. Although JAs are known to be collagen-rich tumours, single collagens have not been analysed so far. This investigation aimed to study the expression of the fibrillar collagen types I, II and III in JAs using quantitative RT-PCR $(n=15)$, Western blot analysis $(n=7)$ and immunohistochemical staining $(n=9)$. Nasal mucosa (NM) specimens were used as control tissues. ELISA investigation ( $\mathrm{n}=3$ ) was performed to determine the concentration of C-terminal propeptide of type I collagen in blood serum before and after JA resection. Quantitative RTPCR found significantly elevated Col1A1 $(p<0.001)$, Col1A2 $(p<0.001)$ and Col3A1 $(p<0.001)$ mRNA levels in JAs, compared with NM. Western blot analysis and immunhistochemical staining proved that there is a significant collagen type I and III protein expression in JAs. In none out of 3 patients, ELISA investigation found evidence for elevated concentrations of C-terminal propeptide of type I collagen before tumour resection, compared with postsurgical measurements. Results of the findings using quantitative RT-PCR, Western blot analysis and immunohistochemistry determined that type II collagen is practically absent in JAs. Based on these findings, type I and III collagen are confirmed as being major components of the extracellular matrix in JAs. However, our findings are not encouraging as regards the use of C-terminal Col I propeptid as a suitable serum tumour marker. Our
\end{abstract}

\section{Introduction}

Juvenile angiofibroma (JA) is a rare fibrovascular tumour with specific clinical characteristics of tumour origin, blood supply, sex predominance and growth pattern [Schick and Kahle, 2000]. In contrast to the well-defined histological tumour appearance of irregular configurated vessels embedded in a fibrous stroma [Beham et al., 2000], genetic and molecular alterations have only just started to be elucidated in this unique tumour. Up to now, the focus of interest was on comparative genomic hybridization investigations searching for genetic imbalances, hormone receptor studies, analysis of growth factors and the Wnt signalling pathway, based on the finding of frequent $\beta$-catenin mutations in JAs [Abraham et al., 2001; Schick and Urbschat, 2004].

\section{Abbreviations used in this paper}

JA

NM

PDGF

TGF- $\beta$ juvenile angiofibroma

nasal mucosa

platelet-derived growth factor transforming growth factor- $\beta$

\section{KARGER}

Fax +4161306 1234

E-Mail karger@karger.ch

www.karger.com
(C) 2008 S. Karger AG, Basel

$1422-6405 / 09 / 1896-0403 \$ 26.00 / 0$

Accessible online at:

www.karger.com/cto
Dr. Bernhard Schick, PD

Department of Otolaryngology, Head and Neck Surgery

University Erlangen-Nuremberg

Waldstrasse 1, DE-91054 Erlangen (Germany)

Tel. +49 9131853 3631, Fax +49 9131853 4778, E-Mail bernhard.schick@uk-erlangen.de 
So far, only 2 JA studies have dealt with the extracellular matrix, one of which was concerned with the immunohistochemical analysis of laminin expressions [Starlinger et al., 2007], the other with the investigation of gelatinase/collagenase activity [Duerr et al., 2008]. Although JAs are known to be collagen-rich tumours with evidence for increased gelatinase/collagenase activity, so far, investigation of single collagens has not been performed.

Collagens are important extracellular matrix proteins which provide not only structural functions by building up fibrils (collagen types I, III, V and XI), beaded filaments (type VI collagen) and networks (type IV, VIII and X collagen) but which also perform diverse biological functions (interaction with other matrix proteins and cellular receptors). It is further interesting that single collagens are characteristic for specific tissues, especially as tumour origin from periost or embryonal cartilage has been suggested for JAs [Schick et al., 2002]. In most connective tissues, collagen type I is the major structural component. Type II collagen is a major component of cartilage [van der Rest and Garrone, 1991], whereas type III collagen was first isolated from tissues containing collagen type I. Thus, the collagen expression pattern may hint at a tumour origin that has still not been finally defined with respect to JAs.

The collagen genes are widely distributed in the genome with a huge number of gene mutations already proven. A complex processing of highly specific posttranslational enzymes (among others, prolyl 4-hydroxylase; $\mathrm{N}$ and $\mathrm{C}$ proteinases) is needed to modify the larger precursor molecules (procollagens) to form the fibrilforming collagens. The fibrillar collagens are similar in size, built up of 3 chains forming characteristic triple helixes [Prockop and Kivirikko, 1995]. Collagen type I is usually composed of 2 identical $\alpha 1$ (I) and 1 distinct $\alpha 2$ (I) chain assembling the triple helix. In pathological conditions, collagen type I fibrils can contain $3 \alpha 1$ (I) chains resembling a homotrimer [Ottani et al., 2002]. Collagen types II and III are homotrimers built up of $3 \alpha 1$ chains.

As the extracellular matrix is important in tumour biology, improved knowledge of the extracellular matrix structure in JAs is needed. This report comprises the first analysis of fibrillar collagen expression (collagen types I, II and III) in this unique fibrovascular tumour.

\section{Materials and Methods}

Tissue Samples

Tissues from 15 JAs and 8 inferior turbinates which had been snapped frozen immediately after surgical removal were available for this study. Diagnosis of JA in the treated male patients (age
Table 1. PCR conditions and primer sequences used for quantitative RT-PCR

\begin{tabular}{|c|c|c|c|}
\hline & $\begin{array}{l}\text { Optimal } \\
\text { temperature, }{ }^{\circ} \mathrm{C}\end{array}$ & $\begin{array}{l}\text { Concentration, } \\
\mathrm{pmol} / \mu \mathrm{l}\end{array}$ & Sequences \\
\hline$\beta$-Actin & 54.4 & $\begin{array}{l}0.3 \text { forward } \\
0.3 \text { reverse }\end{array}$ & $\begin{array}{l}\text { cctggcacccagcacaat } \\
\text { gggccggactcgtcatac }\end{array}$ \\
\hline Col1A1 & 59.7 & $\begin{array}{l}0.5 \text { forward } \\
0.5 \text { reverse }\end{array}$ & $\begin{array}{l}\text { caatggtgctcctggtattgct } \\
\text { ctgttacccttgggaccagga }\end{array}$ \\
\hline Col1A2 & 66 & $\begin{array}{l}0.5 \text { forward } \\
0.5 \text { reverse }\end{array}$ & $\begin{array}{l}\text { ggtgaacctggtcaaactggtc } \\
\text { cctgtggtccaacaactcctct }\end{array}$ \\
\hline Col2A1 & 55.8 & $\begin{array}{l}0.6 \text { forward } \\
0.6 \text { reverse }\end{array}$ & $\begin{array}{l}\text { ctgctggagtcaagggtgat } \\
\text { ctgtctccttgcttgccagt }\end{array}$ \\
\hline Col3A1 & 55 & $\begin{array}{l}0.6 \text { forward } \\
0.3 \text { reverse }\end{array}$ & $\begin{array}{l}\text { gccccgtattatggagatga } \\
\text { ggggtttttacgagaaccatc }\end{array}$ \\
\hline
\end{tabular}

13-26 years) was already evident preoperatively, based on the characteristic clinical findings and proved by detailed histopathological evaluation, as reported in previous studies [Schick et al., 2006]. Tumour stages according to Andrews et al. [1989] ranged from stage II to IIIb in the series presented. Nasal mucosa (NM) tissue derived from inferior turbinate surgery for treatment of nasal obstruction was used as control tissue. For Western blot analysis, collagen type I protein (C7774, Sigma-Aldrich, Munich, Germany) and protein extractions from a leiomyosarcoma of the paranasal sinuses, ear cartilage as well as trachea cartilage were used as positive controls. Protein extractions from tonsils served as negative controls.

\section{Quantitative Real-Time PCR}

RNA was extracted from JAs, NM tissue and ear cartilage using Ultra Thurax 25 ( IKA-Labortechnik, Staufen, Germany) for homogenization and RNeasy Plus Mini Kit (Qiagen, Hilden, Germany) according to the manufacturer's protocol. After DNase I digestion, $1 \mu \mathrm{g}$ RNA was reverse-transcribed to cDNA by QuantiTect Reverse Transcription Kit (Qiagen).

The 20- $\mu$ l reaction mix contained 1.6 $\mu \mathrm{l}$ cDNA (diluted 1:10), $10 \mu l$ Mastermix (QuantiTect SYBR Green PCR Kit, Qiagen) and the primers at the various tested optimal concentration (table 1). Real-time PCR was performed in triplets for each cDNA on iCycler (Bio-Rad Laboratories, Munich, Germany). Standard curves for quantifying the copy number were generated using respective products from former test PCR, which were directly cleaned up or extracted from agarose gel after electrophoresis. The purified template cDNA allowed serial dilutions for different copy numbers $\left(10^{3}-10^{8}\right)$. For absolute quantification, the copy number of target genes was extrapolated from the standard curve equation, and the concentration was finally normalized to copies of the target gene per 1,000 copies of $\beta$-actin.

\section{Western Blot Analysis}

Collagen extraction was performed using 2 different lysis buffers. The first aim was the extraction of soluble proteins using a buffer containing $50 \mathrm{~mm}$ Tris ( $\mathrm{pH} 7.4), 0.5 \mathrm{M} \mathrm{NaCl}, 10 \mathrm{mM}$ EDTA and protease inhibitor cocktail (Complete, Roche Diagnostics, Mannheim, Germany). The remaining pellet was dis- 
solved in a second buffer containing $50 \mathrm{mM}$ Tris (pH 7.4), $6 \mathrm{M}$ urea, $1 \%$ NP40, $10 \mathrm{~mm}$ EDTA and $0.05 \mathrm{~m} \beta$-mercaptoethanol. After determination of the protein concentration (BCA-test, Pierce, Bonn, Germany) and denaturation, equal protein amounts $(50 \mu \mathrm{g})$ were prepared for SDS gel electrophoresis. After electrophoresis, proteins were transferred to Nitrocellulose Transfer Membrane (Protran BA 83, Schleicher \& Schuell, Dassel, Germany) by overnight electroblotting at $4^{\circ} \mathrm{C}$ in $10 \mathrm{~mm}$ sodium tetraborate decahydrate at $120 \mathrm{~mA}$. Following staining with Ponceau $\mathrm{S}$ at room temperature, the nitrocellulose membrane was blocked with Roti Block solution (Carl-Roth, Karlsruhe, Germany) overnight. Incubation with the monoclonal mouse anti-collagen type I (sc-59772, 1:200, Santa Cruz Biotechnology, Santa Cruz, Calif., USA), monoclonal mouse anti-collagen type II (Ab-2: 2B1.5, 1:200, Dianova, Hamburg, Germany) and monoclonal mouse anti-collagen type III (CSO 007-01, 1:1,000, Dianova) antibodies was carried out for $90 \mathrm{~min}$ at room temperature. Secondary antibody conjugated to horse radish-peroxidase was diluted in Roti Block and applied to the nitrocellulose membrane for $60 \mathrm{~min}$ at room temperature. The antibody signal was visualized by chemiluminescence. After incubation with enhanced chemiluminescence reagent $(2.5 \mathrm{mM}$ luminol in DMSO, $0.5 \mathrm{mM}$ p-coumaric acid in DMSO, 0.1 M Tris$\mathrm{HCl}, 0.015 \% \mathrm{H}_{2} \mathrm{O}_{2}, \mathrm{pH}$ 8.5) for $1 \mathrm{~min}$, signals were detected by the LumiImager F1 (Roche Diagnostics).

\section{Immunohistology}

Immunohistology was performed using $5-\mu \mathrm{m}$ cryosections. Sections were blocked with $2 \%$ normal horse serum (Linaris, Wertheim-Bettingen, Germany) and incubated overnight at $4^{\circ} \mathrm{C}$ with the primary antibodies (1:100), as described for Western blot analysis before. For visualization, ImmPress Reagent (Linaris) and Peroxidase Substratkit AEC (Linaris) was used according to the manufacturer's protocol. Counterstaining with hematoxylin followed. Omissions of the primary antibodies were used as negative controls.

\section{ELISA}

Collagen type I ELISA (Metra Cicp, Osteomedical, Bünde, Germany) for quantitative measurement of the C-terminal propeptide of type I collagen was performed according to the manufacturer's protocol. The given standards of known protein content derived from human fibroblasts were used to determine the serum concentration.

\section{Statistical Analysis}

Statistical analysis was used for each candidate to confirm or refute the null hypothesis stating that 'mRNA expression is not different in juvenile angiofibromas compared with NM tissue'. Two-tailed Wilcoxon rank-sum tests $(\alpha=0.05)$ were performed with the $\mathrm{p}$ values adjusted according to Bonferroni.

\section{Results}

Quantitative real-time PCR was first used to analyse Col1A1, Col1A2, Col2A1 and Col3A1 mRNA expression in $15 \mathrm{JAs}$ and $8 \mathrm{NM}$ tissues. Values obtained after normalization of the detected copy numbers of the target gene per
1,000 copies of $\beta$-actin showed statistically significant higher mRNA expression levels for Col1A1 ( $p<0.001$, adjusted), Col1A2 ( $\mathrm{p}<0.001$, adjusted) and Col3A1 ( $<<$ 0.001 , adjusted) in JAs compared with NM (fig. 1). The highest values were found for Col1A2 (mean value in JAs: $28,321 \pm 46,642$ copies per 1,000 copies of $\beta$-actin; mean value in NM: $247 \pm 162$ copies per 1,000 copies of $\beta$ actin), followed by CollA1 (mean value in JAs: 6,085 \pm 7,761 copies per 1,000 copies of $\beta$-actin; mean value in NM: $89 \pm 44$ copies per 1,000 copies of $\beta$-actin) and Col3A1 (mean value in JAs: $3,189 \pm 4,020$ copies per 1,000 copies of $\beta$-actin; mean value in NM: $140 \pm 103$ copies per 1,000 copies of $\beta$-actin). In regard to the observed high deviation between the values obtained for different tumours, we found no correlation of the values obtained for Col1A1, Col1A2 or Col3A1 in JAs with tumour stage. While the Col2A1 primers clearly detected Col2A1 mRNA in cartilage used as control tissue, almost no Col2A1 mRNA expression was found in JAs and NM specimens.

In a further step, we analysed collagen type I, II and III expression on the protein level by Western blot analysis of 7 JAs and 5 NM specimens. As indicated by previous quantitative RT-PCR, we found prominent type I collagen bands of different molecular weight in all JAs, but only slight type I collagen bands in NM (fig. 2a, b). Different protein bands are well known in fibrillar collagens, indicating procollagens and collagen aggregates $[\mathrm{Xu}$ et al., 2000]. We were not able to prove collagen type II protein expression in JAs and NM by Western blot analysis (data not shown). Similar to our findings for collagen type I, Western blot analysis proved prominent collagen type III protein bands in all JAs which were not observed in the NM probes (fig. 2c).

As we were interested in analysing collagen protein expression on tissue sections, immunohistological studies were performed on 9 JAs and 4 NMs. For both collagen types I and III, in JAs, we detected prominent staining in the subepithelial basilar membrane at the surface, in the tumour stroma and in the vascular extracellular matrix (fig. 3a, b). In NM, we observed an intense staining of the subepithelial basal membrane and a less intense type I and III collagen staining in the submucosal extracellular matrix (fig. 3c, d). Type II collagen showed neither staining in JAs nor in NM (data not shown).

Finally, with regard to our observation of prominent collagen type I protein expression in JAs, we were interested in the possibility of elevated serum levels of C-terminal propeptide of type I collagen in JA patients. As blood serum was available from 3 patients affected by a stage II tumour from both before and 1 year after JA re- 


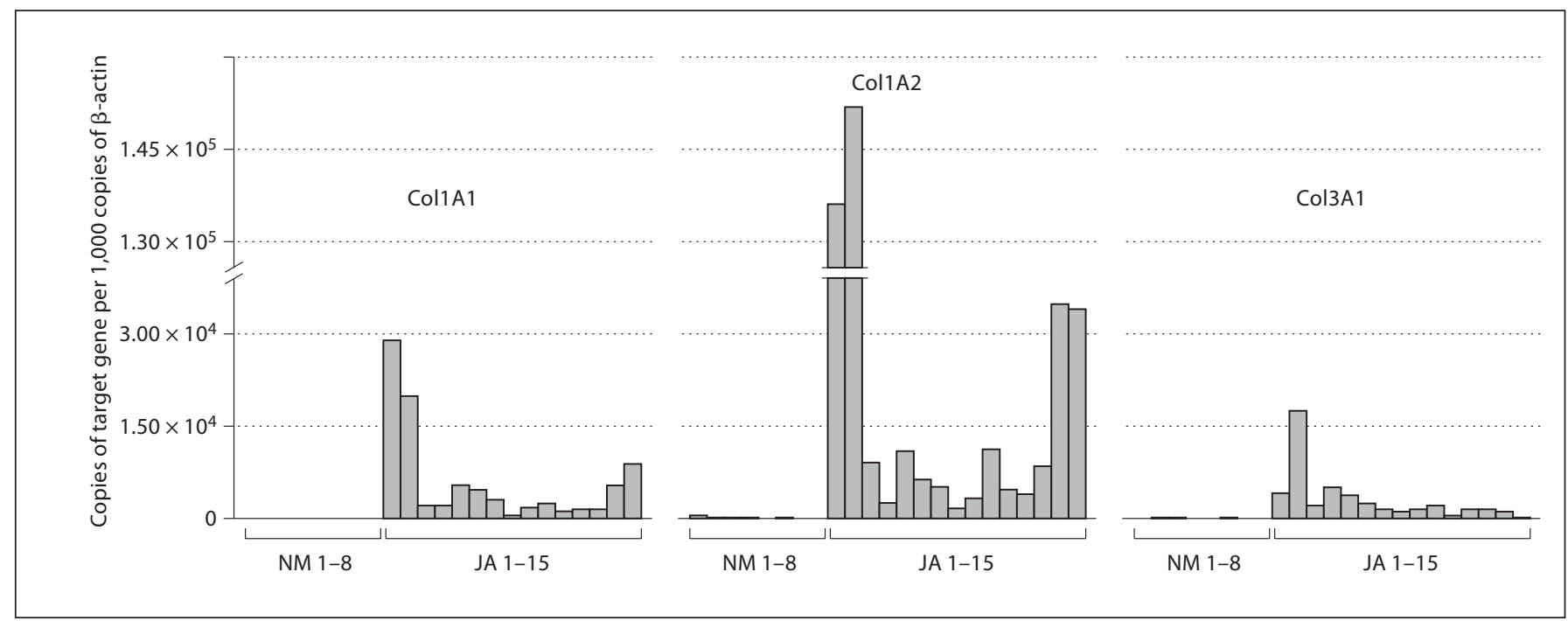

Fig. 1. Findings of quantitative real-time PCR for Col1A1, Col1A2 and Col3A1 mRNA expression in JAs $(\mathrm{n}=15)$ and NM specimens $(n=8)$ normalized to copies of the target gene per 1,000 copies of $\beta$-actin. Standard deviation is indicated but not visible due to its

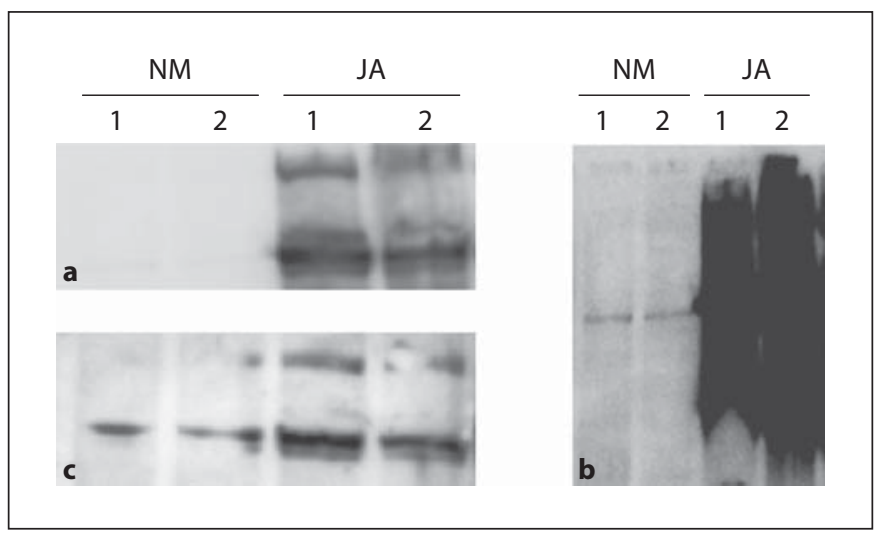

Fig. 2. Western blot findings for collagen type I (a) and collagen type III (c) protein expression in NM specimens $(n=2)$ and JAs $(\mathrm{n}=2)$ indicate procollagen and fibril-forming collagen bands in JAs as well as higher protein expression levels for both collagens in JAs compared with NM. Longer exposure time proves collagen type I bands in NM specimens and illustrates the high collagen type I protein expression in JAs (b).

section, we performed an ELISA investigation for C-terminal propeptide of type I collagen. In none of the 3 patients, the serum level of C-terminal propeptide of type I collagen was higher before than after tumour resection (table 2). Serum from patients with nasal obstruction treated by inferior turbinate surgery was not available. small size. The high deviation between the values obtained from different JAs showed no correlation with the tumour stage, but may reflect on the varying ratio of the vessels to the fibrous tumour component in JAs.

\section{Discussion}

Our study indicates (1) collagen types I and III as major JA extracellular matrix components with increased transcriptional and translational expression levels compared with NM, (2) higher mRNA levels for CollA2 than for CollA1 in JAs, (3) no clear evidence for elevated blood C-terminal Col I propeptid concentrations in case of JA manifestation, and (4) almost no type II collagen expression at the mRNA and protein levels in this rare fibrovascular tumour.

Since 1853, numerous theories have been suggested to explain the aetiology of JAs. During the 19th and 20th centuries, embryonal cartilage was one of the assumed tumour origins [Schick et al., 2002]. The results of our study which prove that collagen type II expression is practically non-existent in JAs serve to refute the theory that JAs may have their origins in cartilage tissue. In addition, we detected a significant expression of type I collagen in JAs, a factor which has previously been found in numerous connective tissues, but not in cartilage [Byers, 2000].

Our observation that the level of Col1A2 expression in JAs was higher than that of Col1A1 mRNA may give further support to another theory of JA aetiology. The suggestion that remnants of the first branchial arch artery are incorporated into the vascular tumour component 

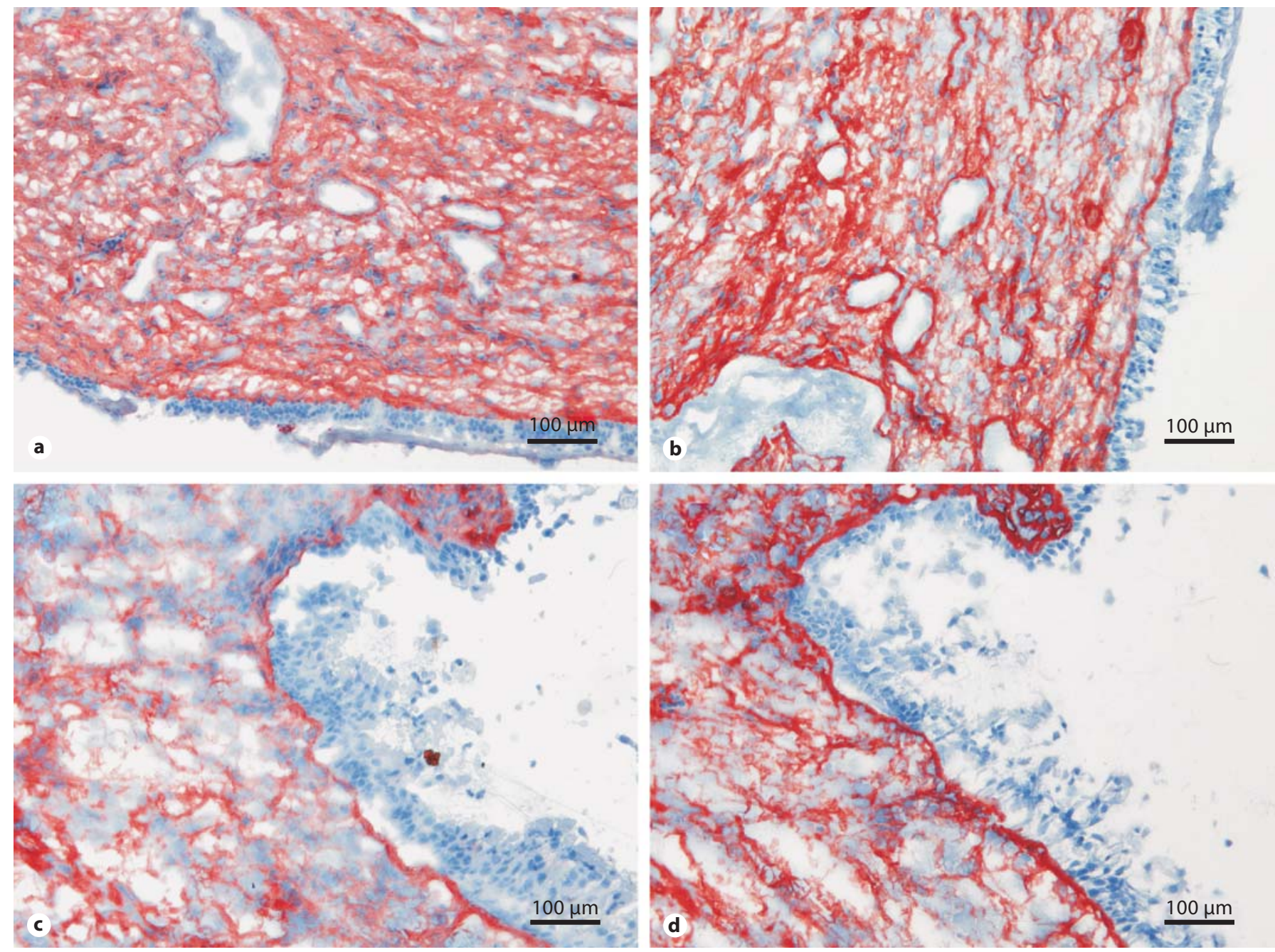

Fig. 3. Immunohistochemical staining for collagen type I (a) and type III (b) in JAs indicates a prominent protein expression in the subepithelial membrane and stromal as well as vascular extracellular tumour matrix. In NM specimens, a similar but less intense submucosal extracellular matrix staining was observed for type I (c) and type III collagen $(\mathbf{d})$.

[Schick et al., 2002; Schick and Urbschat, 2004] has attracted attention, as this embryological perspective allowed 4 characteristic tumour features to be explained for the first time: origin, location, blood supply and vascular architecture in JAs. The recent detection of laminin $\alpha 2$ expression in JA vessels indicating vessels of early developmental stage supported the assumption that plexus remnants of the first branchial arch artery are involved in tumour development [Starlinger et al., 2007]. In the neural crest of the branchial arch, as well as in the mesoderm, there have been findings of derived mesenchymal cells. While cranial neural crest cells give rise, among other things, to the frontonasal skeleton, some portions
Table 2. Concentrations of C-terminal propeptide of type I collagen in blood serum $(\mathrm{ng} / \mathrm{ml})$ derived from 3 patients before and after tumour resection (only stage II tumours) determined by ELISA investigation

\begin{tabular}{lcc}
\hline Patient & $\begin{array}{l}\text { Before tumour } \\
\text { resection }\end{array}$ & $\begin{array}{l}\text { After tumour } \\
\text { resection }\end{array}$ \\
\hline 1 & $7 \pm 1$ & $8 \pm 0$ \\
2 & $25 \pm 4$ & $27 \pm 2$ \\
3 & $32 \pm 2$ & $33 \pm 5$ \\
\hline
\end{tabular}


of the skull vaults and maxillary cartilage, mesodermal cells are involved in the formation of the skeletal muscles of the face and lower jaw [Bhattacherjee et al., 2007]. Interestingly, a comparison of the neural crest and mesoderm lineage-dependent gene expression of cells derived from the first branchial arch in mice found, among other genes, a higher Col1 A2 expression in the neural crest-derived mesenchyme [Bhattacherjee et al., 2007]. Thus, our observation that the expression of Col1A2 was higher than that of Col1A1 mRNA may mean that the neural crest cells of the first branchial arch are involved in JA origin.

With regard to the significant expression of collagen type I in JAs, the transforming growth factor- $\beta$ (TGF- $\beta$ ) is of great interest, as TGF- $\beta_{1}$ has been the subject of several studies concerning JAs. In these studies, staining of activated TGF- $\beta_{1}$ in fibroblasts and endothelial cells of JAs [Dillard et al., 2000] and high levels of TGF- $\beta_{1}$ in the stroma of strong vascularized tumours [Schuon et al., 2007] were among the results reported. Interestingly, the multifunctional cytokine TGF- $\beta$ stimulates, beside its numerous other fundamental roles - in embryonic development, cell growth and differentiation, regulation of immune and inflammatory responses, angiogenesis, tissue repair/regeneration and apoptosis - collagen synthesis and fibroblast proliferation [Chen et al., 2006]. In mesenchymal cells, TGF- $\beta$ is known to be a potent inducer of Col1A1 and Col1A2 gene transcription [Chen et al., 2006; Okano et al., 2006] and it gives rise to fibrosis in the lung, heart, liver and kidney [Mishra et al., 2007]. Hereby, TGF- $\beta$ does not only stimulate matrix accumulation, but also reduces matrix degradation, for example due to the upregulation of protease inhibitors [Verrecchia and Mauviel, 2004].

Taking into consideration these TGF- $\beta$ functions together with our finding of strong Col1A1 and Col1A2 expression in JAs, it is likely that TGF- $\beta$ is involved in tissue fibrosis in this rare tumour. As the result of immunohistochemichal findings in JAs, TGF- $\beta_{1}$ has already been suggested as playing a role in the development of the fibrous tumour component [Nagai et al., 1996]. In addition to the role of collagen type I in fibrosis, the accumulation of type I collagen is involved in cell adhesion, chemotaxis and migration [Mishra et al., 2007] processes that might also be present in JAs.

Independent of or parallel to TGF- $\beta$, further stimulation of the Col1A2 promoter by other cytokines such as IL-4 and IL-13 has been reported [Ramirez et al., 2006]. This is of special interest in JAs, as inflammatory cells have been proven to form a significant cell population in this tumour [Wendler et al., 2007]. Inflammatory cells must further be considered as a source for TGF- $\beta$ in fibrosis in addition to their function of interleukin release [Feghali-Bostwick et al., 2007]. Another interesting candidate potentially involved in collagen synthesis in JAs is the platelet-derived growth factor (PDGF), as PDGF- $\beta$ mRNA has been reported to be overexpressed in $50 \%$ of JAs, compared with normal inferior turbinates [Nagai et al., 1996]. PDGF has been found to trigger CollA2 upregulation in primary human fibroblasts [Ramirez et al., 2006]. Thus, the expression of distinct growth factors might be another explanation for the higher level of Col1A2 expression compared with the CollA1 mRNA expression in JAs, in addition to the possible involvement of neural crest-derived mesenchymal cells in tumour origin.

In individual cases, findings of a decrease in tumour size and vascularity have been reported after oestrogen treatment prior to the surgical removal of JAs [Johns et al., 1980]. Evidence of oestrogen-induced attenuation of type I collagen expression has been reported in diabetic kidney disease [Dixon and Maric, 2007] and may be similar in JAs. Chemotherapy has rarely been used in JA treatment. Cases have been described in which adriamycin and dacarbazin are combined [Schick et al., 1996]. Interestingly, 5-fluorouracil has been identified as a potent inhibitor of TGF- $\beta / \mathrm{Smad}$ signalling-induced Col1A2 gene expression [Verrecchia and Mauviel, 2004].

In summary, we were able to define collagen types I and III as major components of the stromal and vascular extracellular matrix in JAs. Our preliminary results on C-terminal Col I propeptide analysis in blood samples before and after tumour resection are not encouraging as regards the use of C-terminal Col I propeptide as a suitable serum tumour marker. The interesting finding of higher levels of Col1 A2 expression than of Col1A1 mRNA expression in JAs might be the consequence of the growth factors defined above, or a further indicator for an embryological tumour origin. Our finding that type II collagen expression is practically absent in JAs refutes the theory that tumours have their origins in cartilage tissue.

\section{Acknowledgment}

This work was kindly supported by the Robert Pfleger grant to B. Schick. 


\section{References}

Abraham, S.C., E.A. Montgomery, F.M. Giardiello, T.T. Wu (2001) Frequent beta-catenin mutations in juvenile nasopharyngea angiofibromas. Am J Pathol 158: 10731078.

Andrews, J.C., U. Fisch, A. Valavanis, U. Aeppli, M.S. Makek (1989) The surgical management of extensive nasopharyngeal angiofibromas with the infratemporal fossa approach. Laryngoscope 99: 429-437.

Beham, A., C. Beham-Schmid, S. Regauer, L. Auböck, H. Stammberger (2000) Nasopharyngeal angiofibroma: true neoplasm or vascular malformation? Adv Anat Pathol 7: 3646.

Bhattacherjee, V., P. Mukhopadhyay, S. Singh, C. Johnson, J.T. Philipose, C.P. Warner, R.M. Greene, M.M. Pisano (2007) Neural crest and mesoderm lineage-dependent gene expression in orofacial development. Differentiation 75: 463-477.

Byers, P.H. (2000) Collagens: building blocks at the end of the development line. Clin Genet 58: $270-279$.

Chen, S.J., H. Ning, W. Ishida, S. Sodin-Semrl, S Takagawa, Y. Mori, J. Varga (2006) The early-immediate gene EGR-1 is induced by transforming growth factor- $\beta$ and mediates stimulation of collagen gene expression. J Biol Chem 281: 21183-21197.

Dillard, D.G, C. Cohen, S. Muller, J. Del Gaudio, O. Reichman, B. Parrish, D. Rackley, A.A. Gal (2000) Immunolocalization of activated transforming growth factor beta 1 in juvenile nasopharyngeal angiofibroma. Arch Otolaryngol Head Neck Surg 126: 723-725.

Dixon, A., C. Maric (2007) 17Beta-estradiol attenuates diabetic kidney disease via regulating extracellular matrix and transforming growth factor-beta protein expression and signalling. Am J Physiol Renal Physiol 293: F1678-F1690.
Duerr, S., O. Wendler, T. Aigner, S. Karosi, B. Schick (2008) Metalloproteinases in juvenile angiofibroma - a collagen rich tumor. Hum Pathol 39: 259-268.

Feghali-Bostwick, C.A., C.G. Tsai, V.G. Valentine, S. Kantrow, M.W. Stoner, J.M. Pilewski, A. Gadgil, M.P. George, K.F. Gibson, A.M. Choi, N. Kaminski, Y. Zhang, S.R. Duncan (2007) Cellular and humoral autoreactivity in idiopathic pulmonary fibrosis. J Immunol 179: 2592-2599.

Johns, M.E., R.M. MacLeod, R.W. Cantrell (1980) Estrogen receptors in nasopharyngeal angiofibromas. Laryngoscope 90: 628-634.

Mishra, R., L. Zhu, R.L. Eckert, M.S. Simonson (2007) TGF- $\beta$-regulated collagen type I accumulation: role of Src-based signals. Am J Physiol Cell Physiol 292: C1361-C1369.

Nagai, M.A., O. Butugan, A. Logullo, M.M. Brentani (1996) Expression of growth factors, proto-oncogenes, and p53 in nasopharyngeal angiofibromas. Laryngoscope 106: 190-195.

Okano, K., H.W. Schnaper, K. Bomsztyk, T. Hayashida (2006) RACK1 binds to Smad 3 to modulate transforming growth factor- $\beta_{1}$ stimulated $\alpha 2(\mathrm{I})$ collagen transcription in renal tubular epithelial cells. J Biol Chem 281: 26196-26204.

Ottani, V., D. Martini, M. Franchi, A. Ruggeri, M. Raspanti (2002) Hierarchical structures in fibrillar collagens. Micron 33: 587-596.

Prockop, D.J., K.I. Kivirikko (1995) Collagens: molecular biology, diseases, and potentials for therapy. Annu Rev Biochem 64: 403434.

Ramirez, F., S. Tanaka, G. Bou-Gharios (2006) Transcriptional regulation of the human $\alpha 2$ (I) collagen gene (COL1A2), an informative model system to study fibrotic diseases. Matrix Biol 25: 365-372.

Schick, B., G. Kahle (2000) Radiological findings in angiofibroma. Acta Radiol 41: 585-593.
Schick, B., G. Kahle, R. Hässler, W. Draf (1996) Chemotherapy of juvenile angiofibroma - an alternative? HNO 44: 148-152.

Schick, B., P.K. Plinkert, A. Prescher (2002) Aetiology of angiofibromas: reflection on their specific vascular component. Laryngorhinootologie 81: 280-284.

Schick, B., S. Urbschat (2004) New aspects of pathogenesis of juvenile angiofibroma. Hosp Med 65: 269-273.

Schick, B., S. Wemmert, V. Jung, W.I. Steudel, M. Montenarh, S. Urbschat (2006) Genetic heterogeneity of the MYC oncogene in advanced juvenile angiofibromas. Cancer Genet Cytogenet 164: 25-31.

Schuon, R., J. Brieger, U.R. Heinrich, Y. Roth, W. Szyfter, W.J. Mann (2007) Immunohistochemical analysis of growth mechanisms in juvenile nasopharyngeal angiofibroma. Eur Arch Otorhinolaryngol 264: 389-394.

Starlinger, V., M. Gramann, O. Wendler, B. Schick (2007) Laminin expression in juvenile angiofibromas indicates vessel's early developmental stage. Acta Otolaryngol 22: $1-6$.

van der Rest, M., R. Garrone (1991) Collagen family of proteins. FASEB J 5: 2814-2823.

Verrecchia, F., A. Mauviel (2004) TGF- $\beta$ and TNF- $\alpha$ : antagonistic cytokines controlling type I collagen gene expression. Cell Signal 16: $873-880$

Wendler, O., R. Schäfer, B. Schick (2007) Mast cells and T-lymphocytes in juvenile angiofibromas. Eur Arch Otorhinolaryngol 264: 769-775.

Xu, C., C.K. Zarins, H.S. Bassiouny, W.H. Briggs, C. Reardon, S. Glagov (2000) Differential transmural distribution of gene expression for collagen types I and III proximal to aortic coarctation in the rabbit. J Vasc Res 37: 170182 